\title{
Incidence of Multidimensional Poverty Among Riverine Households in Southwestern Nigeria
}

\author{
O. A. C. Ologbon ${ }^{1}$, A. O. Idowu ${ }^{1}$, K. K. Salmonu ${ }^{2} \&$ I. B. Oluwatayo ${ }^{2}$ \\ ${ }^{1}$ Department of Agricultural Economics and Farm Management, Olabisi Onabanjo University, Yewa Campus, \\ Ayetoro, Ogun State, Nigeria \\ ${ }^{2}$ Department of Agricultural Economics, University of Ibadan, Nigeria \\ Correspondence: O. A. C. Ologbon, Department of Agricultural Economics and Farm Management, Olabisi \\ Onabanjo University, Yewa Campus, Ayetoro, Ogun State, Nigeria. E-mail: chrislogem@yahoo.com
}

Received: March 5, 2014 Accepted: April 6, 2014 Online Published: April 15, 2014

doi:10.5539/jas.v6n5p167 URL: http://dx.doi.org/10.5539/jas.v6n5p167

\begin{abstract}
What constitutes poverty transcends the lack of income but generally captures such other subjective and supplementary aspects that represent human functioning and capability. This view enables the design and implementation of policies to alleviate poverty among the poor, especially the riverine households with their attendant risks. Data were obtained from 448 riverine households in South-western Nigeria to examine the level of multidimensional deprivation and poverty among them. The mean household size was 5 ; fifty-six (56\%) having less than minimum 9 year compulsory and basic education; only about $16 \%$ of them having members gainfully engaged and about $68 \%$ of the household heads engaging in Onshore livelihood activities. Majority $(60.3 \%)$ of the households suffered deprivation in eight indicators $(61.54 \%$ of the total possible number of deprivation) and above, all (100\%) of the riverine households being adjudged poor in about $6 \%, 12 \%$ and $19 \%$ respectively' of the thirteen dimensions of deprivation. At dual cutoff value $(k=8)$, the adjusted multidimensional poverty rate of the households $\left(M_{0}=0.3422\right)$; adjusted poverty gap $\left(M_{l}=0.1608\right)$, and poverty severity $\left(M_{2}=0.0761\right)$ showed high level of inequality among the deprived households. Conclusively, poverty was manifested in basic standard of living commodities and services among the riverine households as indicated by their low level of education, limited access to hygienic source of drinking water, food, energy, health care, toilet facilities as well as improved means of livelihood.
\end{abstract}

Keywords: welfare indicators, riverine households, multidimensional poverty, onshore activities

\section{Introduction}

Poverty is regarded as a complex manifestation of socio-economic deprivation of which income is only one aspect. Therefore, other non-monetary (or supplementary) variables need to be included into the analysis of poverty and social exclusion, determined by appropriately weighed indicators to reflect the degree of deprivation as well as the various sources (dimensions) of poverty as experienced by the households (Maggio, 2004). In contemporary times, multidimensional approaches have been developed with the scope of achieving a more comprehensive analysis and measurement of poverty. The view of poverty as multiple deprivation will better provide the basic information for the design and implementation of policies to reduce the relative proportion of the poor as well as the intensity of poverty in society. Thus, poverty has more recently been addressed (e.g, Okunmadewa, 2002; Oyekale \& Okunmadewa, 2011) from a multidimensional viewpoint by stakeholders in the development arena.

Poverty is multifaceted according to the types of deprivation, and it is also gender and age specific. It consists in any form of inequity, which is a source of social exclusion, in the distribution of the living conditions essential to human dignity. These living conditions correspond to the capabilities of individuals, households and communities to meet their basic needs in such areas as income, education, health, food/nutrition, safe water/sanitation, labor/employment, housing (living environment), access to productive assets, access to markets, and community participation/social peace (Asselin, 2009). Poverty has often times been seen as a state of deprivation and is manifested in illiteracy, lack of access to water, poor housing and declining purchasing power (e.g, Adepoju, 2001). 
The coastal areas in Nigeria predominantly comprise of fishing communities/settlements of varying sizes mostly located on the edge of freshwater forest and on the top of beach ridges. There are about 20 millions of such people living along the coastline stretching some $800 \mathrm{Km}$ in length (Ibe \& Awosika, 2004). Many of these riverine households are exposed to risky situations occasioned by devastating natural/environmental hazards such as erosions and floods which have perpetually subjected them to a situation of homelessness, hopelessness, reduced welfare status and abject poverty (Siyanbade, 2006). A study by Sardar et al. (2008) revealed that riverine households often do not find adequate and appropriate shelters; quality food and drinking water; adequate and hygienic sanitation; privacy for women, particularly for the lactating mothers and adolescent women. In addition, floods often force students out of academic activities since their learning centers are often used as makeshift flood shelters in affected riverine areas.

Wherever they exist, coastal regions are mostly affected by the scourge of poverty with lives and property at the risk of flooding and erosion and the situation can make even a riverine community within an urban metropolis far worse than rural areas (Sardar et al., 2008). The situation in the Nigeria coastal region is not in any way different as the combined consequences of flooding, erosion and crude-oil exploration often produce a shock in the local economy that results in decreasing economic activities (both onshore and offshore) leading to decreasing crop outputs and fish catch, with an attendant increase in poverty level and welfare loss (Maduagwu, 2000). Oyekale (2010) in a poverty study across rural Nigeria reported that in the coastal south-southern zone of the country, relative poverty was particularly high in Akwa Ibom (5.06\%); Bayelsa (1.18\%); Cross River (2.57\%); Delta (3.32\%); and Rivers (2.84\%) among other southern States. This variation in the poverty level within a geographic zone underscores the need to pay particular attention to riverine communities when designing national policy intervention programmes to alleviate poverty. This study had examined the incidence of multidimensional poverty among riverine households in southwestern Nigeria and constructed a profile of poverty according to selected households' socio-economic characteristics.

\section{Methodology}

\subsection{Study Area}

The empirical setting for this study is the coastal area of southwest geo-political zone of Nigeria characterized by the existence of lagoon, the Atlantic ocean and brackish water. Three states (namely Ogun, Ondo and Lagos) having these characteristic features were selected for this study. The southwestern zone lies within Latitude $5.45^{\circ} \mathrm{N}$ and $8.15^{\circ} \mathrm{N}$ and Longitude $3^{\circ} \mathrm{E}$ and $6^{\circ} \mathrm{E}$, with a temperature range of $27^{\circ} \mathrm{C}$ and $32^{\circ} \mathrm{C}$. The coastal bed of Southwest geo-political zone of Nigeria has artisanal and commercial capture fishing activities as the predominant occupation among the settlers, as well as homestead culture fishing that is undertaken by some households but to a smaller extent. Land-based farming activities such as crop and livestock rearing are also practiced in some upland communities either as primary occupation by permanent inhabitants of these communities or as secondary activity by displaced riverine settlers who occasionally migrate to the upland areas at the time of floods. Households in the coast of Southwestern Nigeria also engage in natural resource collection such as sharp sand from the lagoon bed and sea shores, as well as games, fuel wood and timber and non-timber products from the brackish water-dominated forest area. The climate in the study area also favours the growing of arable and tree crops such as cassava, yam and grains, as well as tree crops such as cocoa, rubber, kolanut, among others, the production of which is predominantly characterized by small-holder, subsistence practices.

\subsection{Source of Data and Methods of Data Collection}

Primary data were used for this study. Primary data were obtained with the aid of structured questionnaires that were administered on the household head. Information were collected mainly on the socio-economic, demographic, and community-specific variables that bothered on the welfare status of the riverine households. Sixteen welfare indicators (categorized under five dimensions) directly linked to Millennium Development Goals (MDGs) were used in examining the multidimensional poverty structure of the households, namely Education (year of schooling, child enrolment in schools); Health (method of malaria treatment, self-reported health); Food and Nutrition (food availability, food sufficiency); Standard of Living (source of drinking water, cooking fuel, toilet type, means of solid waste disposal, material of the wall of the house, material of the floor of the house, source of domestic lighting, ownership of basic assets); and Social Affiliation (political participation, social participation).

\subsection{Sampling Procedure and Sample Size}

A five-stage sampling procedure was adopted. In the first stage, Ogun, Ondo and Lagos States were purposively selected as they contain the coastal areas of the Southwest geo-political zone of Nigeria. Three (3) Local Government Areas (LGAs) belonging in the core coastal area of the three States were purposively selected at the 
second stage. They were Ogun waterside, Ipokia and Ijebu-East LGAs in Ogun State; Ilaje, Ese-Odo and Irele LGAs in Ondo State and Epe, Badagry and Ibeju/Lekki LGAs in Lagos State. Subsequent stages involved a proportional selection of 20 political wards at the third stage and 100 riverine communities at the fourth stage. In the final stage, 5 households $(\mathrm{HH})$ were proportionally selected per community, targeting a maximum of 500 households for the stud. However, responses from only 448 questionnaires were used while others were discarded for incomplete information. The proportionality factor used in the third stage to select wards is given below:

\subsection{Estimation Procedures}

\subsubsection{Determination of Welfare Deprivation Among the Riverine Households}

The starting point for measuring dimensional poverty following the Alkire-Foster (2007) approach adopted in this study is to determine the level of welfare deprivation among the surveyed households. Achieving this objective involved identifying the number of welfare deprivations suffered by riverine households in Southwestern Nigeria, starting with an identification function $\rho(y ; z)$ yielding the set $Z \subseteq\{1, \ldots, n\}$ of households who are poor in $y$ given $z$, where:

$y=$ household deprivation vector, and $z=$ vector of dimensional deprivation cutoff

$\rho\left(y_{i} ; z\right)=1$ if household $i$ is poor, and $\rho\left(y_{i} ; z\right)=0$ if otherwise.

$g^{0}=\left\lfloor g_{i j}^{0}\right\rfloor$ is an $n \times d$ matrix of deprivations associated with $y$, where $g_{i j}^{0}=1\left(=w_{j}\right)$ when $y_{i j}<z_{j}$, and $g_{i j}^{0}=0$ when $y_{i j} \geq z_{j}(i$ and $j$ represent individual household and dimension, respectively).

The $i^{\text {th }}$ row vector of $g^{0}$, denoted by $g_{i}^{0}$, is the deprivation vector for the $i^{\text {th }}$ household. From matrix $g^{0}$ a column vector $c$ of deprivation counts was constructed whose $i^{\text {th }}$ entry $c_{i}=\left|g_{i}^{0}\right|=\sum_{j=1}^{d} g_{i j}^{0}$ is the sum of weighted deprivations suffered by household $i$. The vector $c$ identifies the number of welfare dimensions in which the poor households are deprived, which is the incidence of deprivation.

\subsubsection{Multidimensional Poverty Measures}

In order to profile poverty of the riverine households, multidimensional poverty measures were computed, following Bourguignon and Chakravarty (2003), as used by Alkire and Foster (2007) and Alkire and Santos (2010). The multidimensional poverty measures are defined as:

$$
M_{\alpha}=\mu\left(g^{\alpha}(k)\right) \text { for } \alpha \geq 0
$$

where $\alpha$ is a poverty aversion parameter which takes on values 0,1 , or 2 . The general form of the dimension-adjusted poverty index (MPI) is denoted by $M_{\alpha}(y ; z)$ where $y$ represents the household's level of achievement in any given indicator, and $\mathrm{z}$ represents the dimension-specific cut-off for the indicator. In another expression,

$$
M_{\alpha}=\frac{\left|g^{\alpha}(k)\right|}{n d}
$$

where $\mathrm{d}$ represents the number of dimensions and $\mathrm{n}$ is the total number of sampled households. The variable $g^{\alpha}$ is an $n \times d$ matrix whose $i j^{\text {th }}$ entry is 1 when household $i$ is deprived in the $j^{\text {th }}$ dimension, and 0 otherwise, with $i^{t h}$ row vector $g_{i}^{\alpha}$ being the household $i$ 's deprivation vector. In this case, $M_{\alpha}$ is defined as the quotient of the sum of the $\alpha$ powers of the normalized gaps of the poor and the highest possible value for this sum.

When $\alpha=0$,

$$
M_{0}=\mu\left(g^{0}(k)\right)
$$


The notation $\mu$ portrays $M_{0}$ as the mean of the matrix $g^{0}(k)$, that is,

$$
M_{0}=\frac{\left|g^{0}(k)\right|}{n d}
$$

where $n$ and $d$ are number of sampled observation and dimensions, respectively.

$M_{0}$ is a product of two quantities, the deprivation share $A$ given as: $A=|c(k)| /(q d)$, and $H$, incidence of multidimensional poverty, $H=\frac{q}{n}$ Thus,

$$
M_{o}=H A=\mu\left(g^{0}(k)\right)
$$

where $q=q(y ; z)$ is the number of poor households in the set $Z_{k}$, and hence the number of households identified to be multidimensionally deprived based on the dual cutoff criterion, $\rho_{k}$. The notation $c_{i}(k) / d$ represents the fraction of weighted indicators in which the poor household $i$ is deprived given the cut-off $k . M_{0}$ is thus the dimension-adjusted Headcount Ratio.

When $\alpha=1$, the dimension-adjusted poverty gap, $M_{1}(y ; z)$ results, defined as:

$$
M_{1}=H A G=\mu\left(g^{1}(k)\right)
$$

$\mathrm{G}=$ average poverty gap across all dimensions in which the poor households are deprived, given as

$$
G=\left|g^{1}(k)\right| /\left|g^{0}(k)\right|
$$

where $g^{1}(k)$ is a censored matrix defined by $g_{i j}^{1}(k)=0$ if $c_{i}<k$ and $g_{i j}^{1}(k)=g_{i j}^{1}$ if $c_{i} \geq k$, so that $g^{1}(k)$ only includes the deprivations of the poor.

When $\alpha=2$, the dimension-adjusted poverty severity $M_{2}(y ; z)$ results, expressed as

$$
M_{2}=H A S=\mu\left(g^{2}(k)\right)
$$

where $\mathrm{S}=$ average severity of deprivation across all dimensions in which the poor households are deprived,

$$
S=\left|g^{2}(k)\right| /\left|g^{0}(k)\right|
$$

For any defined increase in deprivation, the $M_{2}$ measure registers a greater impact the larger the initial level of

deprivation. Indeed, $M_{2}=\left(M_{1}\right)^{2}+V$, where $V$ is the variance among all normalized gaps given as:

$$
V=\sum_{i} \sum_{j}\left(\left(\mu\left(g^{\prime}\right)-g_{i j}^{\prime}\right)^{2} / n d\right.
$$

In terms of the deprivation vector $c, M_{2}=\left(M_{1}\right)^{2}\left\lfloor 1+C^{2}\right\rfloor$ where

$$
C^{2}=V /\left(\mu\left(g^{\prime}\right)\right)^{2}
$$

\section{Results and Discussions}

\subsection{Households' Socio-Economic Characteristics}

Table 1 shows the socio-economic characteristics of sampled riverine households. The mean household size was 5 with medium-sized households having between 7 and 12 members making the largest percentage (about 45\%). About $84 \%$ of the households had members that were non-working as a result of under-age, over-age or other factors; while $77.46 \%$ and $94.42 \%$ have a maximum of $\$ 50000$ either as monthly income or external remittance. The larger proportion (about 71\%) of the households did not meet the Federal Government of Nigeria (FGN) policy of minimum educational attainment of Junior Secondary School (i.e, 9 years of formal education), with only about $9 \%$ of them having members with tertiary education. This reflects a gross educational deprivation among the respondent households. Majority $(72.10 \%)$ were male, mostly $(38.84 \%)$ polygamous with mean age of $46 \pm 10.94$ years. About $68 \%$ of the household heads engaged in fishing and 
on-shore natural resource collection activities, in which sector about $70 \%$ of this number had acquired not less than 10 years of experience. Only 142 (about 32\%) of the household heads engaged in off-shore occupational activities which included peasant farming, $81.92 \%$ of them cultivating less than 2 hectares of farm land.

The multidimensional nature of poverty in the study area, as described above, has well been adjudged as the consequence of lacking various welfare goods/services necessary to maintain a minimum level of living, such as health, income, human capital (literacy), housing condition, access to public services, employment opportunities, to mention but few. For instance, major environmental problems associated with low agricultural productivity, high vulnerability to health hazards and poor infrastructural developments (such as network roads, markets, means of communications, among others) have been linked with the high incidence of poverty in the rural areas of Nigeria (Alayande \& Alayande, 2004). In addition to these, Okunmadewa (1999) have also identified low level of education, high fertility rate, lack of access to improved seeds and inputs, social amenities as being grossly responsible for the poverty status of many households in the Nigerian rural economy. Thus, early exit from the poverty circle is more of an illusion among the rural poor if the present socio-economic situation persists (Oyekale \& Okunmadewa, 2008).

Table 1. Households' socio-economic characteristics

\begin{tabular}{|c|c|c|}
\hline $\begin{array}{l}\text { Characteristic } \\
\text { Age (Years) }\end{array}$ & Frequency & Percentage $(\%)$ \\
\hline$<31$ & 63 & 14.06 \\
\hline $31-40$ & 63 & 14.06 \\
\hline $41-50$ & 175 & 39.06 \\
\hline $51-60$ & 108 & 24.11 \\
\hline$>60$ & 39 & 8.71 \\
\hline Total & 448 & \multirow{2}{*}{100.00} \\
\hline Mean $=46$ & S.D $=10.94$ & \\
\hline \multicolumn{3}{|l|}{ Gender } \\
\hline Male & 323 & 72.10 \\
\hline Female & 125 & 27.90 \\
\hline Total & 448 & 100.00 \\
\hline \multicolumn{3}{|l|}{ Marital Status } \\
\hline Single & 65 & 14.51 \\
\hline Married (monogamous) & 125 & 27.90 \\
\hline Married (polygamous) & 174 & 38.84 \\
\hline Separated/Divorced & 41 & 9.15 \\
\hline Widowed & 43 & 9.60 \\
\hline Total & 448 & 100.00 \\
\hline \multicolumn{3}{|l|}{ Primary Occupation } \\
\hline Fishing/Natural Resource Collection & 306 & 68.30 \\
\hline Offshore Activities & 142 & 31.70 \\
\hline Total & 448 & 100.00 \\
\hline \multicolumn{3}{|l|}{ Household Size } \\
\hline $1-6$ & 199 & 44.42 \\
\hline 7- 12 & 202 & 45.09 \\
\hline$>12$ & 47 & 10.49 \\
\hline Total & 448 & 100.00 \\
\hline
\end{tabular}


\begin{tabular}{ll}
\hline Mean $=5$ & $S . D=3.0168$
\end{tabular}

Dependency Ratio

71

15.85

$0.1-0.50$

303

67.63

$0.6-1.0$

74

16.52

Total

448

Mean $=0.41$

S.D $=0.4263$

100.00

Formal Education Status

No Formal Education $\quad 80$

17.86

Primary Education

169

37.72

Junior Secondary Education

68

15.18

Senior Secondary/Vocational Education

94

20.98

Tertiary Education

37

8.6

Total

448

100.00

Spouse/Child(ren) Working

Yes

84.15

No

71

15.85

Total

448

100.00

Monthly Household Income (\#)

$<10,000$

37

8.26

$10,000-50,000$

310

69.20

$50,001-100,000$

89

19.87

$100,001-150,000$

12

2.68

Total

Mean $=$ A37, 115.94.00

448

$S . D=\mathrm{N} 23,298.97$

100.00

Monthly External Remittances (\#)

$<10,000$

349

77.90

$10,000-50,000$

74

16.52

$>50,000$

25

5.58

Total

448

Mean $=$ A3,909.00

$S . D=N 9475.69$

Source: Field survey data, 2010.

\subsection{Households' Deprivation Counts}

Table 2 presents the number and percentage of deprivations suffered by the riverine households, based on the indicator-specific cutoff, $\left(z_{j}\right)$. Only five of the eight 'standard of living' variables were satisfactorily retained in the process of rescaling of the sixteen initial welfare variables, the remaining three indicators (wall material, cooking fuel, and means of solid waste disposal) having been found redundant. Thus, only thirteen of the welfare indicators initially proposed for exploring the multidimensionality of poverty in the study area were subsequently included in the analysis. As evidenced from Table 2, none of the surveyed households suffered deprivation in exactly one or two welfare indicators, depicting the true multidimensional poverty status of the riverine households. Only three (0.7\%); seven $(1.6 \%)$ and twenty-one $(4.7 \%)$ households suffered deprivation in exactly three, four and five dimensions, respectively. Percentage of the riverine households that experienced deprivation in exactly six (11.6\%); seven (21.2\%); eight (22.3\%); nine (19.0\%) and ten (13.6\%) indicators was relatively larger than the other groups. Observably from Table 2, the greater percentage $(22.3 \%)$ of the 
households suffered deprivation in eight (61.54\% of the total possible number of deprivation) indicators, beyond which value the number of deprivations suffered diminished gradually. Again, intuitively, none of the households suffered multiple deprivation in as many as thirteen indicator variables.

Table 2. Distribution of households' deprivation counts

\begin{tabular}{lll}
\hline No. of deprivations suffered & Number of households & $\%$ of households deprived \\
\hline One & 0 & 0 \\
Two & 0 & 0 \\
Three & 3 & 0.7 \\
Four & 7 & 1.6 \\
Five & 21 & 4.7 \\
Six & 52 & 11.6 \\
Seven & 95 & 21.2 \\
Eight & 100 & 22.3 \\
Nine & 85 & 19.0 \\
Ten & 61 & 13.6 \\
Eleven & 20 & 4.5 \\
Twelve & 4 & 0.9 \\
Thirteen & 0 & 0 \\
\hline
\end{tabular}

Source: Field survey data, 2010.

\subsection{Welfare Deprivation among Riverine Households}

Table 3 presents the extent of households' deprivation in the welfare variables as a follow up on the deprivations counts, based on the within- and across-dimension dual cutoff value, (k). Summary statistics presented in Table 3 shows that the proportion of riverine households deprived in each dimension ranges from $5.8 \%$ for "participation in community development projects", to $97.5 \%$ for "source of drinking water". By implication, $94.2 \%$ of the riverine households participated in the various community development programmes engaged in by the respondents as their communal contributions to reducing their suffering within the neighbourhood. Prominent among the reported projects were erection of passage planks on the flowing stream (common among core Riverine households), onshore security surveillance against pilferages of fishing gadget and catches, as well as forming community self-help vigilance groups against robbery, attack and violence.

For the education, health and food/nutrition dimensions, households were more endowed in one (i.e, 50\%) of the two indicators making up each of those welfare dimensions. In about $71 \%$ of the surveyed households, no household had a member with the minimum required universal basic education of nine years (Junior Secondary education) as set under the Nigerian education policy to achieve the second millennium development goal (MDG2). This has implication for the inability of members the coastal households to disengage from artisanal fishing activities to take up formal sector employment thus further worsening their poverty situation. However, only few (about 20\%) of the households have school-age children (6-15 years) not presently enrolled in school, giving an indication that deprivation in the education dimension may only be temporary among the riverine households. This finding underscores the Education For All (EFA) policy of the Federal Government of Nigeria (FGN) to have all children, particularly girls, to have access to complete, free and compulsory primary education of good quality by the year 2015 (NEEDS, 2004).

Sixty-six (66\%) of the households either visited registered hospitals, patronize drug sellers or used insecticide treated bed nets to treat/prevent malaria outbreak, while over $60 \%$ of them had adult members with self-reported health status below average. By implication, coastal households are gradually having better access to modern healthcare delivery services but more awareness may be required to sustain this emerging trend. In terms of food adequacy, less than $15 \%$ of the households had children aged 6-15 years feeding on less than 2 major meals per day while food was available to close to $46 \%$ of the surveyed households. This observed food sufficiency may have also been closely linked to the improving health condition of members of the coastal households. 
Obviously, level of material deprivation was more prominent within the living condition dimension as only in two (basic assets and domestic lighting) of the five indicators were households not deprived, representing $40 \%$ of the indicators within this dimension. Only $2.5 \%$ of the households had access to drinking water from protected wells, boreholes or pipe-borne water. Majority (97.5\%) of the households obtained water from unprotected wells, springs, rivers, lagoons, rains, stagnant water and forest creeks that were common within their neighbourhood. All the households were however relatively endowed in the two indicators that make up the social integration dimension which is a reflection of high level of social capital among the riverine households in political and community development activities.

Table 3. Incidence of deprivation among riverine households $(k=8)$

\begin{tabular}{|c|c|c|c|c|}
\hline $\begin{array}{l}\text { Welfare } \\
\text { Dimension }\end{array}$ & Welfare Indicator & $\begin{array}{l}\text { Number of } \\
\text { deprived } \\
\text { households }\end{array}$ & $\begin{array}{l}\text { Percentage of } \\
\text { deprived } \\
\text { households }\end{array}$ & $\begin{array}{l}\% \text { of dimension in } \\
\text { which } \mathrm{H} / \text { holds are } \\
\text { non-deprived }\end{array}$ \\
\hline \multirow{2}{*}{ Education } & Year of schooling & 317 & $\begin{array}{l}70.8 \\
(0.0215)\end{array}$ & \multirow{2}{*}{$50 \%$} \\
\hline & Children school enrolment & 89 & $\begin{array}{l}* 19.9 \\
(0.0189)\end{array}$ & \\
\hline \multirow{2}{*}{ Health } & Self-reported health & 273 & $\begin{array}{l}60.9 \\
(0.0230)\end{array}$ & \multirow{2}{*}{$50 \%$} \\
\hline & $\begin{array}{l}\text { Method of malaria } \\
\text { treatment/control }\end{array}$ & 153 & $\begin{array}{l}{ }^{*} 34.1 \\
(0.0224)\end{array}$ & \\
\hline \multirow{2}{*}{ Food/Nutrition } & No. of meals per day & 65 & $\begin{array}{l}{ }^{*} 14.5 \\
(0.0167)\end{array}$ & \multirow{2}{*}{$50 \%$} \\
\hline & Monthly food Expenditure & 241 & $\begin{array}{l}53.8 \\
(0.0236)\end{array}$ & \\
\hline \multirow{5}{*}{$\begin{array}{l}\text { Household living } \\
\text { condition }\end{array}$} & Material of the floor & 443 & $\begin{array}{l}94.4 \\
(0.0000)\end{array}$ & \multirow{5}{*}{$40 \%$} \\
\hline & Domestic light & 53 & $\begin{array}{l}{ }^{*} 11.8 \\
(0.0153)\end{array}$ & \\
\hline & Toilet type & 400 & $\begin{array}{l}89.3 \\
(0.0146)\end{array}$ & \\
\hline & Source of drinking water & 437 & $\begin{array}{l}97.5 \\
(0.0073)\end{array}$ & \\
\hline & Household assets & 113 & $\begin{array}{l}{ }^{*} 25.2 \\
(0.0205)\end{array}$ & \\
\hline \multirow[b]{2}{*}{ Social Integration } & Political affiliation & 69 & $\begin{array}{l}{ }^{*} 15.4 \\
(0.0171)\end{array}$ & \multirow[b]{2}{*}{$100 \%$} \\
\hline & $\begin{array}{l}\text { Participation in } \\
\text { community development } \\
\text { projects }\end{array}$ & 26 & $\begin{array}{l}{ }^{*} 5.8 \\
(0.0111)\end{array}$ & \\
\hline
\end{tabular}

Source: Field survey data, 2010.

Figures in parentheses are the standard errors.

${ }^{*}$ Welfare indicators in which households were relatively more endowed compared to the 50 percentile. 


\subsection{Household Multidimensional Poverty Measures}

\subsubsection{Identification of Multidimensionally Poor Households}

Table 4 shows the number and percentage of riverine households identified as been poor with deprivation in varying number of poverty indicators. With deprivation benchmark (cutoff $k$ ) set at 1,2 and 3 indicating deprivation in at least one, two or three welfare dimensions respectively, all (i.e, 100\%) the sampled households were identified as being poor. This presents a situation where all the riverine households were adjudged poor in about $6 \%, 12 \%$ and $19 \%$ respectively' of the thirteen dimensions of deprivation considered. Increasing the cutoff to six $(k=6)$ shows a slight change in the poverty condition of the households as over $93 \%$ of the households are still adjudged poor. Generally, for any seven of the thirteen indicators considered, over $81 \%$ of the total households were identified poor reflecting a high level of multidimensional poverty among the riverine households. At the other extreme when deprivation in 13 indicators is required as a condition for being poor, none of the riverine households was adjudged to be poor. Intervening values of cutoff ( $k$ between 4 and 12) reveal households who are poor in a specified number but not in all thirteen indicators. The number of households identified as poor declines at an increasing rate as the number of deprivation increases up till the ninth indicator. At welfare level up to ten, eleven and twelve, the number of poor households declines at a decreasing rate until it fades out to zero.

Table 4. Descriptive statistics of multidimensionally poor households (varying cutoff value)

\begin{tabular}{llll}
\hline $\begin{array}{l}\text { Value of } \\
\text { cutoff }(k)\end{array}$ & $\begin{array}{l}\text { Number of MPI poor } \\
\text { households }\end{array}$ & $\begin{array}{l}\text { Percentage of the households that } \\
\text { is MPI poor }(\%)\end{array}$ & $\begin{array}{l}\text { Marginal increase in number of } \\
\text { poor households }\end{array}$ \\
\hline $1^{*}, 2,3$ & 448 & 100 & - \\
4 & 445 & 99.3 & 3 \\
5 & 438 & 97.8 & 7 \\
6 & 417 & 93.1 & 21 \\
7 & 365 & 81.5 & 52 \\
8 & 270 & 60.3 & 95 \\
9 & 170 & 38.0 & 100 \\
10 & 85 & 19.0 & 85 \\
11 & 24 & 5.4 & 61 \\
12 & 4 & 0.89 & 20 \\
$13^{* *}$ & None & None & - \\
\hline
\end{tabular}

Source: Field survey data, 2010.

$\left({ }^{*}\right.$ and ${ }^{* *}$ value of cutoff $(\mathrm{k})=1$ and 13 is the union and intersection approach, respectively).

\subsubsection{Multidimensional Poverty Headcount Ratio (H)}

The percentage of households that are MPI poor and experiencing deprivation in certain number of weighted indicators according to the cutoff value is depicted on Table 5. Two adjoining cases to the intermediate cutoff position ( $k=6$ and $k=10$ ) were also presented for comparison. For the intermediate $(k=8)$ position, 270 (i.e, $60.3 \%$ ) of the households were multidmensionally poor with deprivation in 8 (about $62 \%$ ) of the weighted indicators. This censored headcount value is different from the traditional headcount in three ways: firstly, it is the proportion of households that are deprived in some combination of one to three indicators (i.e, $50 \%$ of the weighted indicators within a dimension) and deprived in each dimension. Secondly, the headcount refers to the percentage of households with individual members deprived that are affected by some levels of deprivation, bearing in mind the concept of poverty by inclusion. Therefore, households that were deprived in a particular indicator but still not considered as being multidmensionally poor were not included in this headcount. For instance, if a household has a child of school age not registered in school, such a household is considered deprived in education but may not necessarily be poor within the multidimensional context of poverty analysis. This makes the headcount in the multidimensional sense to be different from the traditional definition of literacy headcount - the percentage of people who are themselves educationally deprived. Thirdly, contrary to the usual 
trend in unidimensional poverty identification, the number of households adjudged to be multidimensionally poor decreased as the dual cutoff value increased. Therefore, moving the cutoff value from 6 to 10 showed a remarkable decline in the proportion (and percentage) of the riverine households that were identified as being multidmensionally poor, from 417 (93.1\%) to 85 (19\%), respectively.

At the one extreme, all (i.e, 100\%) the surveyed households were identified as being multidmensionally poor in the case of union criterion $(k=1)$ where deprivation in any one dimension/indicator were enough to identify a household as been poor. This satisfies the axiomatic condition that the union identification approach often predicts high numbers, identifying a large percentage of the population as being poor in the multidimensional sense (in consonance with the findings of Chakravarty et al., 1998; Bourguignon and Charavarty, 2003; and Alkire \& Eli, 2010;). In the case of intersection criterion $(k=13)$ where deprivation in all 13 indicators (or all 5 dimensions) is required as poverty identification criterion, no household was particularly poor (similar to the findings of Alkire \& Seth, 2008). There is a clear indication that the households were mostly deprived in 7 to 10 weighted indicators as already indicated on Table 2.

Table 5. Incidence of multidimensional poverty (at $\mathrm{k}=8 \equiv 62 \%$ of 13 indicators)

\begin{tabular}{lllll}
\hline \multirow{2}{*}{ Cutoff value } & \multicolumn{2}{l}{ Deprived households (MPI poor) } & Non-deprived households (MPI non-poor) \\
\cline { 2 - 5 } & Frequency & Percentage (\%) & Frequency & Percentage (\%) \\
\hline $\mathrm{k}=1$ & 448 & 100 & 0 & 0 \\
$\mathrm{k}=6$ & 417 & 93.1 & 31 & 6.9 \\
$\mathbf{k}=\mathbf{8}$ & $\mathbf{2 7 0}$ & $\mathbf{6 0 . 3}$ & $\mathbf{1 7 8}$ & $\mathbf{3 9 . 7}$ \\
$\mathrm{k}=10$ & 85 & 19 & 363 & 81 \\
$\mathrm{k}=13$ & 0 & 0 & 448 & 100 \\
\hline
\end{tabular}

Source: Field survey data, 2010.

\subsubsection{Adjusted Multidimensional Poverty Measures}

From Table 6, the value of the headcount ratio is 0.603 when $\mathrm{k}=8$ (representing about $62 \%$ of the 13 final poverty indicators considered). The implication of this is that $60.3 \%$ or 270 of the riverine households are poor when deprivation in exactly eight indicators is required to consider a household multidimensionally poor. The adjusted multidimensional poverty rate of the households $\left(M_{0}\right)$ at $\mathrm{k}=8$ is 0.3422 . The value of the adjusted poverty gap $\left(M_{I}=0.1608\right)$ showed a deepening of the deprivation of households in the identified dimensions. Poverty severity $M_{2}(=0.0761)$ showed a further decrease in value reflecting a $21.90 \%$ level of inequality among deprived states of the poor households.

Table 6. Poverty incidence, depth and severity (at $\mathrm{k}=8$ )

\begin{tabular}{ll}
\cline { 2 - 2 } Poverty Measures & $k=8$ \\
\hline $\mathrm{H}$ & 0.6030 \\
$\mathrm{M}_{0}$ & 0.3422 \\
$\mathrm{M}_{1}$ & 0.1608 \\
$\mathrm{M}_{2}$ & 0.0761 \\
\hline
\end{tabular}

Source: Field survey data, 2010.

\subsubsection{Multidimensional Poverty Profile by Household Socio-Economic Characteristics}

The size of riverine households strongly affects the pattern of multidimensional poverty indices as depicted on Table 7. The result shows an increase in multidimensional poverty incidence, intensity and severity as household size increases. There was a slight increase in the proportion of poor households from $33.26 \%$ to $35.69 \%$ for small-sized and medium-sized households, respectively. Similar trend was noticed for poverty depth as $15.55 \%$, $17.18 \%$ and $43.75 \%$ of small-sized, medium-sized and large-sized households were trapped below the multidimensional poverty cutoff. In like pattern, $7.22 \%, 8.48 \%$ and $20.78 \%$ of small-sized, medium-sized and 
large-sized households were severely poor in the five welfare dimensions considered. In all cases, the percentage increase in poverty index was more prominent as household size increased beyond 12 members. This trend is in consonance with the findings of Agboola et al. (2004).

Table 7. Multidimensional poverty profile by households' socio-economic characteristics

\begin{tabular}{|c|c|c|c|}
\hline Household Characteristics & $\begin{array}{l}\text { Multidimensional } \\
\text { Poverty Incidence } \\
\left(M_{0}\right)\end{array}$ & $\begin{array}{l}\text { Multidimensional } \\
\text { Poverty Depth } \\
\left(M_{1}\right)\end{array}$ & $\begin{array}{l}\text { Multidimensional } \\
\text { Poverty Severity } \\
\left(M_{2}\right)\end{array}$ \\
\hline \multicolumn{4}{|l|}{ Household Size } \\
\hline 1- 6 (small-sized households) & $\begin{array}{l}0.3326 \\
(0.0203)\end{array}$ & $\begin{array}{l}0.1555 \\
(0.0155)\end{array}$ & $\begin{array}{l}0.0722 \\
(0.0084)\end{array}$ \\
\hline 7-12(medium-sized households) & $\begin{array}{l}0.3569 \\
(0.0405)\end{array}$ & $\begin{array}{l}0.1718 \\
(0.0354)\end{array}$ & $\begin{array}{l}0.0848 \\
(0.0194)\end{array}$ \\
\hline$>12$ (large-sized households) & $\begin{array}{l}0.5938 \\
(0.0313)\end{array}$ & $\begin{array}{l}0.4375 \\
(0.1250)\end{array}$ & $\begin{array}{l}0.2078 \\
(0.1101)\end{array}$ \\
\hline Total & $\begin{array}{l}0.3393 \\
(0.0133)\end{array}$ & $\begin{array}{l}0.1607 \\
(0.0106)\end{array}$ & $\begin{array}{l}0.0762 \\
(0.0058)\end{array}$ \\
\hline $\begin{array}{l}F_{\text {value }} \\
\text { Dependency Ratio }\end{array}$ & $0.640^{\mathrm{NS}}$ & $1.092^{\mathrm{NS}}$ & $0.927^{\mathrm{NS}}$ \\
\hline 0 & $\begin{array}{l}0.3768 \\
(0.0328)\end{array}$ & $\begin{array}{l}0.1725 \\
(0.0264)\end{array}$ & $\begin{array}{l}0.0788 \\
(0.0142)\end{array}$ \\
\hline $0.1-0.5$ & $\begin{array}{l}0.3326 \\
(0.0170)\end{array}$ & $\begin{array}{l}0.1592 \\
(0.0135)\end{array}$ & $\begin{array}{l}0.0759 \\
(0.0074)\end{array}$ \\
\hline $0.6-1.0$ & $\begin{array}{l}0.4196 \\
(0.0751)\end{array}$ & $\begin{array}{l}0.2381 \\
(0.0651)\end{array}$ & $\begin{array}{l}0.1123 \\
(0.0372)\end{array}$ \\
\hline Total & $\begin{array}{l}0.3396 \\
(0.0134)\end{array}$ & $\begin{array}{l}0.1610 \\
(0.0106)\end{array}$ & $\begin{array}{l}0.0761 \\
(0.0058)\end{array}$ \\
\hline $\begin{array}{l}F_{\text {value }} \\
\text { Year of Formal Education }\end{array}$ & $0.850^{\mathrm{NS}}$ & $0.622^{\mathrm{NS}}$ & $0.551^{\mathrm{NS}}$ \\
\hline No Formal Education & $\begin{array}{l}0.3781 \\
(0.0291)\end{array}$ & $\begin{array}{l}0.2065 \\
(0.0291)\end{array}$ & $\begin{array}{l}0.1100 \\
(0.0164)\end{array}$ \\
\hline Primary Education & $\begin{array}{l}0.3173 \\
(0.0217)\end{array}$ & $\begin{array}{l}0.1298 \\
(0.0160)\end{array}$ & $\begin{array}{l}0.0599 \\
(0.0085)\end{array}$ \\
\hline Junior Secondary Education & $\begin{array}{l}0.3472 \\
(0.0338)\end{array}$ & $\begin{array}{l}0.1945 \\
(0.0294)\end{array}$ & $\begin{array}{l}0.0961 \\
(0.0162)\end{array}$ \\
\hline Senior Secondary/Vocational Education & $\begin{array}{l}0.3414 \\
(0.0306)\end{array}$ & $\begin{array}{l}0.1386 \\
(0.0193)\end{array}$ & $\begin{array}{l}0.0545 \\
(0.0096)\end{array}$ \\
\hline Tertiary Education & $\begin{array}{l}0.3351 \\
(0.0485)\end{array}$ & $\begin{array}{l}0.1979 \\
(0.0404)\end{array}$ & $\begin{array}{l}0.0967 \\
(0.0224)\end{array}$ \\
\hline Total & $\begin{array}{l}0.3393 \\
(0.0133)\end{array}$ & $\begin{array}{l}0.1607 \\
(0.0106)\end{array}$ & $\begin{array}{l}0.0762 \\
(0.0058)\end{array}$ \\
\hline$F_{\text {value }}$ & $0.655^{\mathrm{NS}}$ & $2.543^{* *}$ & $3.844^{* * *}$ \\
\hline
\end{tabular}




\begin{tabular}{llll}
\hline Household Income & & & \\
$<1000$ & 0.1971 & 0.0510 & 0.3137 \\
& $(0.0295)$ & $(0.0251)$ & $(0.0851)$ \\
$10,000-50,000$ & 0.1568 & 0.0709 & 0.3328 \\
& $(0.0184)$ & $(0.0098)$ & $(0.0326)$ \\
$50,001-100,000$ & 0.1516 & 0.0707 & 0.3341 \\
& $(0.0156)$ & $(0.0084)$ & $(0.0203)$ \\
$100,001-150,000$ & 0.1330 & 0.1030 & 0.3590 \\
& $(0.0526)$ & $(0.0166)$ & $(0.0237)$ \\
Total & 0.1607 & 0.0758 & 0.3414 \\
External Remittances & $(0.0109)$ & $(0.0059)$ & $(0.0137)$ \\
$<10,000$ & & & \\
& & & 0.3390 \\
$10,000-50,000$ & 0.3385 & 0.0621 & $(0.0145)$ \\
$>50,000$ & $(0.1375)$ & $(0.0133)$ & 0.3447 \\
Total & 0.1628 & 0.0777 & $(0.0351)$ \\
& $(0.0116)$ & $(0.0063)$ & 0.4531 \\
\hline
\end{tabular}

Source: Field survey data, 2010.

Figures in parenthesis are the sub-groups contribution to the whole weighted multidimensional poverty measures.

Contrary to expectation, Table 7 also showed that multidimensional poverty incidence, intensity and severity decreased slightly by $4.42 \%, 1.33 \%$ and $0.29 \%$ as dependency ratio increased from zero to 0.5 , but later increased to $41.96 \%, 23.81 \%$ and $11.23 \%$, respectively with an increase in the number of non-working household members (composition of the non-working members of the household as children or aged-adults may likely make no difference going by the low level of external remittances the households receive, as reflected on Table 1). This report agrees with the finding of Riber and Hamrick (2003) and London and Scott (2005) on household poverty level and dependency ratio. Households' educational status significantly influenced the level of multidimensional poverty depth and severity at the $5 \%$ and $1 \%$ confidence level, respectively. As expected, poverty indices were highest among households with no formal education (incidence, 37.81\%; intensity, 20.65\%; and severity, $11.00 \%$ ). There is no particularly clear trend for the poverty indices with increase in the educational attainment of the riverine households. However, the proportion of Riverine households that experienced multidimensional poverty decreased with increase in household income and remittances, while intensity and severity of multidimensional poverty increased gradually as household income and remittances increased.

\section{Conclusion and Recommendations}

The poor households in the riverine communities experience deprivation in a number of welfare commodities, services and activities that requires a mix of poverty reduction interventions to abate. As there exists some level of inequality among the deprived households, poverty reduction intervention programmes should be targeted at different socio-economic groups among the poor. As low human capital development was very prominent among the riverine households, policies that will increase access of households to improved basic educational services should be a priority, such as building of more schools, distribution of educational materials as well as deployment and sustenance of trained teachers in the coastal areas. 


\section{References}

Agboola, P. O., Ikpi, A. E., \& Kormawa, P. M. (2004). Factors Influencing Food Insecurity Among Rural Households in Africa: Results of Analysis from Nigeria. Retrieved from http://www.freewebtown.com

Alkire, S., \& Eli, K. (2010). Multidimensional poverty in developing countries: a measure using existing international data', mimeo, Oxford Poverty and Human Development Initiative. Oxford Department of International Development, University of Oxford.

Alkire, S., \& Foster, J. (2007). Counting and Multidimensional Poverty Measurement. Oxford Poverty and Human Development Initiative, Working Paper No. 7, Oxford Department of International Development, University of Oxford.

Alkire, S., \& Santos, M. E. (2010). Acute Multidimensional Poverty: A New Index for Developing Countries. Oxford Poverty and Human Development Initiative, Working Paper No. 38. Oxford Department of International Development, University of Oxford.

Alkire, S., \& Seth, S. (2008). Multidimensional Poverty and BPL Measures in India: A comparison of Methods. Oxford Poverty \& Human Development Initiative (OPHI) Working Paper 15. Oxford Department of International Development, University of Oxford.

Bourguignon, F., \& Chakravarty, S. (2003). The Measurement of Multidimensional Poverty. Journal of Economic Inequality, 1, 25-49. http://dx.doi.org/10.1023/A:1023913831342

Chakravarty, S. R., Mukherjee, D., \& Ranade, R. (1998). On the Family of Sub-group and Factor Decomposable Measures of Multidimensional Poverty. Research on Economic Inequality, 8, 175-194.

Ibe, A. C., \& Awosika, L. F. (2004). Sea level rise impact on African coastal zones. Journal of Nigeria Institute for Oceanography and Marine Research, 4-153. Retrieved October 3, 2008, from $\mathrm{http} / / \mathrm{www}$.cien.Columbia.edu.docshtml

Maduagwu, A. (2000). Alleviating poverty in Nigeria. Africa Economic Analysis publication, 23(2), 34-41.

Maggio, G. (2004). Multidimensional Analysis of Poverty Dynamics in Great Britain. Institute for Social and Economic Research (ISER) Working Paper.

National Economic Empowerment and Development Strategy (NEEDS). (2004). A publication of the National Planning Commission.

Okunmadewa, F. (1999). International agencies response to poverty situation in Nigeria. CBN Bullion, 23(4), 66-70.

Oyekale, A. S., \& Okunmadewa, F. Y. (2008). Fuzzy Set Approach to Multidimensional Poverty Analysis in Abia State, Nigeria. Journal of Applied Sciences, 3(7), 490-495.

Ribar, D., \& Hamrick, K. (2003). Dynamics of Poverty and Food Insufficiency. Food Assistance and Nutrition Research eport No. 36. Washington, D.C: USDA.

Sardar, M. S., Tahir, M. A., \& Zafar, M. I. (2008). Poverty in riverine areas: Vulnerabilities, social gaps and flood damages. Pakistan journal of life and social sciences, 6(1), 25-31.

Siyanbade, D. O. (2006). Disaster Management in Nigeria: Preparedness and Prevention. Lagos, Nigeria: Olive Tree Publishing Ventures.

\section{Copyrights}

Copyright for this article is retained by the author(s), with first publication rights granted to the journal.

This is an open-access article distributed under the terms and conditions of the Creative Commons Attribution license (http://creativecommons.org/licenses/by/3.0/). 